\title{
Determination of Sub-nmol Hydrogen Peroxide by Electrochemiluminescence of Luminol in Aqueous Solution
}

\author{
Sachiko SakURA and Hideo ImaI \\ Faculty of Pharmaceutical Sciences, Fukuyama University, Fukuyama 729-02
}

\begin{abstract}
An electrochemiluminescence method was developed for determination of sub-nmol hydrogen peroxide in aqueous solution. Luminol was electrochemically oxidized, then reacted with hydrogen peroxide; it emitted light of the maximum wavelength of $436 \mathrm{~nm}$ with a half-life of less than $0.2 \mathrm{~s}$ from the electrode surface. In flow injection analysis a carrier solution (phosphate buffer, $\mathrm{pH} 7-9$ ) containing $17 \mu \mathrm{M}$ luminol was delivered at the flow rate of $0.5 \mathrm{ml} / \mathrm{min}$. The luminescence was detected by a photon counter in a spiral cell under the applied potential of $0.7 \mathrm{~V}$ vs. SCE. A straight line calibration plot was obtained with good reproducibility [RSD $1.6 \%(n=5)]$ in the concentration range of 0.066 to $0.6 \mathrm{nmol}$.
\end{abstract}

Keywords Electrochemiluminescence, flow injection analysis, hydrogen peroxide, luminol

The electrolytically generated chemiluminescence (electrochemiluminescence, ECL) is promising for subnmol analyses coupled with HPLC or FIA, as in the case of fluorescence or electrochemical detection. Blatchford et al. ${ }^{1,2}$ tried to detect some aromatic condensed-ring compounds by ECL in an aprotic mobile phase. But the applications were limited owing to the unstability of anion or cation radical in aqueous solution. One of the purposes of this investigation is to extend the capability to aqueous solutions.

Since hydrogen peroxide is produced by enzymatic reactions through uptake of oxygen, it may be useful for specific detection of the substrates. A lot of investigations have been reported for the determination of hydrogen peroxide at trace levels by electrochemical ${ }^{3}$ or fluorescence ${ }^{4}$ methods; sometimes the method is coupled with enzymatic reactions. ${ }^{5-7}$

Two-step oxidation was required for chemiluminescence of luminol as in the case of indole ${ }^{8}$ or tetracycline. ${ }^{9}$ Usually the oxidation of luminol by potassium ferricyanide was used for this purpose prior to the reaction with hydrogen peroxide. In the method presented in this report, the first oxidation step was replaced by an electrochemical oxidation, namely, luminol is electrochemically oxidized to diazaquinone, then reacts with hydrogen peroxide, and emits luminescence. Since the half life of the luminescence was very short, the light emission confined on the electrode surface allowed a high gain of photon counting. Moreover, this reaction proceeded in neutral aqueous solutions. The application of this method to the flow injection analysis (FIA) of hydrogen peroxide in neutral aqueous solutions at sub-nmol level is presented in this paper.

\section{Experimental}

Cyclic voltammetry $(\mathrm{CV})$

CV was measured by a Fuso Model 312 polarograph equipped with a Hokuto Model HB-104 function generator. The working electrode and counter electrode were two platinum wires: one of $0.5 \mathrm{~mm} \phi$ and 6 $\mathrm{mm} L$ and the other of $0.5 \mathrm{~mm} \phi$ and $3 \mathrm{~cm} L$. SCE was used as the reference electrode. The solution temperature was controlled at $25 \pm 0.1^{\circ} \mathrm{C}$.

\section{Electrochemiluminescence}

A Shimadzu spectrofluorophotometer, Model RF510, was used for measurements of ECL spectra. An Aloka bioluminescence reader, Model BLR-102, was used for photon counting. For fundamental ECL measurements a platinum wire working electrode $\mathbf{( 0 . 5}$ $\mathrm{mm} \phi, 5 \mathrm{~cm} L$, spiral) was used in a Teflon cell $(17 \mathrm{~mm} \phi$, $5 \mathrm{~cm}$ depth). The data acquisition time (integration time) was $30 \mathrm{~s}$ after the applied potential was imposed.

\section{Flow injection analysis}

Carrier solution was delivered by a pump, Toyosoda Kogyo Model CCPD, at a flow rate of $0.5 \mathrm{ml} / \mathrm{min}$. A Teflon coil of $0.25 \mathrm{~mm} \phi$ and $2 \mathrm{~m} L$ was provided in the stream for mixing of injected sample with luminol in the carrier solution.

An ECL flow-through cell, easily constructed by hand, was designed and used as shown in Fig. 1. The solution flowed through the spiral coil of a polyethylene tubing with inner diameter of $0.6 \mathrm{~mm}$. A working electrode (a platinum wire of $0.5 \mathrm{~mm} \phi$ and $10 \mathrm{~cm} L$ ) was 


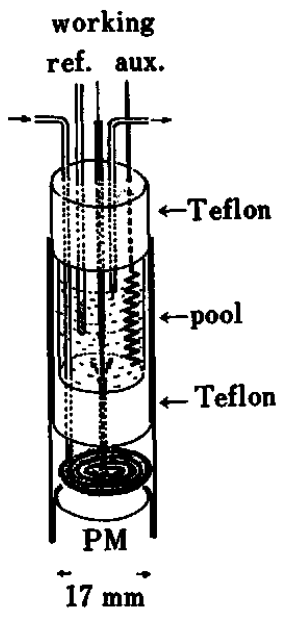

Fig. 1 ECL cell for FIA.

inserted inside of the polyethylene tubing, and one end of the electrode was connected to the outside lead wire in a pool, where a counter electrode (platinum wire, 0.5 $\mathrm{mm} \phi$ and $10 \mathrm{cmL})$ and a reference electrode $(\mathrm{Ag} / \mathrm{AgCl}$; $-0.044 \mathrm{~V}$ vs. SCE) were also set up. The applied potential was controlled at $0.7 \mathrm{~V}$ vs. SCE. The spiral coil was set in front of the PM tube for photon counting.

\section{Reagents}

Luminol (5-amino-2,3-dihydro-1,4-phthalazinedione) was purchased from Wako Pure Chemicals Co., and was purified as follows; The c.p. reagent was dissolved in warm $1 \mathrm{M}$ sodium hydroxide solution, and $0.5 \mathrm{M}$ hydrochloric acid was added slowly to neutralize the solution. The precipitate which formed was filtered and washed well with water. Then it was desiccated at room temperature under reduced pressure. ${ }^{10}$ All other chemicals were of analytical reagent grade, and were used without further purification.

\section{Results and Discussion}

\section{Cyclic voltammetry of luminol}

CV measurements were carried out to establish the optimum applied potential.

Luminol has two dissociation constants: 6.00 and $13.00^{11}$; in a neutral solution it dissociates as a univalent anion. As shown in Fig. 2, the anodic process at $\mathrm{Pt}$ electrode in solution of $\mathrm{pH} 7.4$ consisted of two steps: the first at $0.46 \mathrm{~V}$ and the second at $0.60 \mathrm{~V}$, under the scan rate of $10 \mathrm{mV} / \mathrm{s}$. Under the scan rate of $100 \mathrm{mV} / \mathrm{s}$,

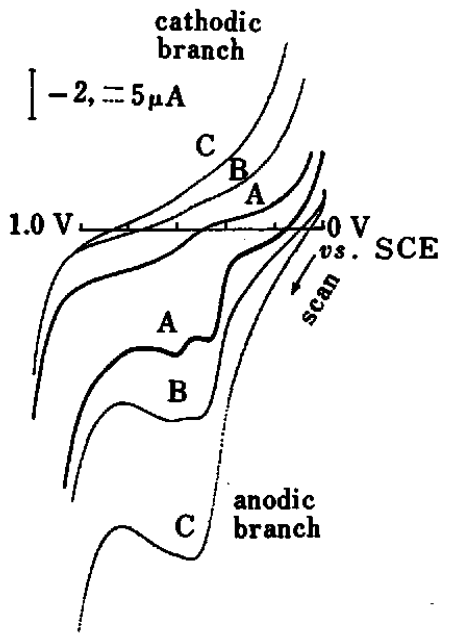

Fig. $2 \mathrm{CV}$ of $2.0 \mathrm{mM}$ luminol at Pt electrode in phosphate buffer (pH 7.4). Scan rate: (A) $10 \mathrm{mV} / \mathrm{s}$, (B) $100 \mathrm{mV} / \mathrm{s}$, (C) $200 \mathrm{mV} / \mathrm{s}$.

the two peaks were still clearly separated, but at 200 $\mathrm{mV} / \mathrm{s}$ they overlapped and an apparent one step oxidation was observed at $0.54 \mathrm{~V}$ under the scan rate greater than $200 \mathrm{mV} / \mathrm{s}$. The oxidation product is diazaquinone $^{12,13}$ as shown in the following. The $\mathrm{pH}$ dependence of the peak potential is expressed with the coefficient of $-50 \mathrm{mV} / \mathrm{pH}$. At a glassy carbon electrode, two-step oxidation was also shown at $\mathbf{0 . 4 8}$ and $0.60 \mathrm{~V} v$ s. SCE, and the third oxidation step, oxidation of amino group, appeared at about $1.10 \mathrm{~V}$ as a small hump in the CV pattern. This third step could not be observed well at the Pt electrode.

\section{Electrochemiluminescence}

The oxidation of luminol by $\mathrm{Fe}$ (III) or $\mathrm{Cu}$ (II) to form diazaquinone in the chemiluminescence procedure was replaced by the electrochemical oxidation, as mentioned in the previous section. Diazaquinone formed at the electrode surface is assumed to change into endoperoxide or hydroperoxide by the reaction with hydrogen peroxide, and an excited state of aminophthalic acid formed by fission of the diazaquinone ring emits light. ${ }^{11}$

Figure 3 shows the dependence of ECL on the applied potential. It is seen that at potentials less than $0.5 \mathrm{~V}$ the luminescence could not be observed, while at more positive potentials the luminescence intensity was increased steeply. The noise level remarkably increased at potentials more positive than $0.7 \mathrm{~V}$, and the $S / N$ ratio showed a maximum at about $0.7-0.9 \mathrm{~V}$, as shown in Fig. 3, curve B.

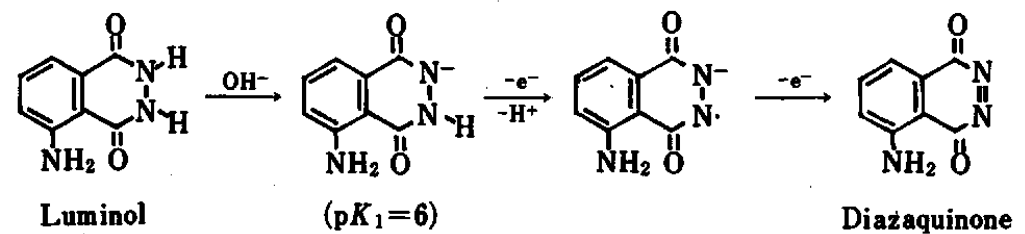




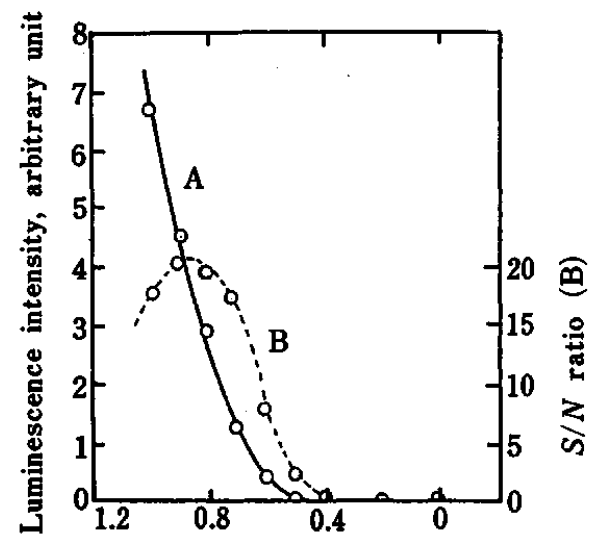

Applied potential/V vs. SCE

Fig. 3 Effect of applied potential on ECL. (A) luminescence intensity, (B) ratio of ECL versus background luminescence, $17 \mu \mathrm{M}$ luminol in phosphate buffer of $\mathrm{pH}$ 7.4, $1.32 \mathrm{nmol}$ hydrogen peroxide.

The maximum wavelength of the emitted light at $\mathrm{pH}$ 7.4 was $436 \mathrm{~nm}$, and in alkaline solution the maximum showed a blue shift. The half-life estimated by the decay curve of emission was less than $0.2 \mathrm{~s}$.

When luminol concentration was changed from 10 $\mathrm{nM}$ to $1 \mathrm{mM}$ under the constant experimental conditions, the luminescence intensity showed a maximum at $10-20 \mu \mathrm{M}$ luminol concentration. At high concentration of luminol the light -emission was interfered by the adsorption of the oxidation product on the electrode surface. The $\mathrm{pH}$ dependence of the luminescence intensity showed a maximum at $\mathrm{pH} 7.4-$ 10 as shown in Fig. 4. In solutions of $\mathrm{pH}$ less than 6, no luminescence was observed. At $\mathrm{pH}$ values higher than 8 , background luminescence was increased; light emission could be observed even in the absence of applied potential at $\mathrm{pH}$ higher than 9 .

\section{Flow injection analysis}

The following experiments were carried out to find out the optimal conditions of FIA: The carrier solution was phosphate buffer ( $\mathrm{pH}$ 7.4) containing $17 \mu \mathrm{M}$ luminol, and the injected quantity of hydrogen peroxide was $1.32 \mathrm{nmol}$.

For the equipment used in this experiment the optimal flow rate was $0.3-0.5 \mathrm{ml} / \mathrm{min}$. The flow rate of $0.5 \mathrm{ml} / \mathrm{min}$ was used throughout the experiments.

In consideration of the $\mathrm{CV}$ data, the potential as high as $0.7 \mathrm{~V}$ was applied to the working electrode. At this potential, the $S / N$ ratio was fairly good and the noise level was sufficiently low.

When acetonitrile was added to the carrier solution, the luminescence intensity was increased at the concentration of $2-5 \%$; its intensity quickly decreased at higher concentrations. The background luminescence was also increased by the addition of acetonitrile. A small quantity of methanol decreased the luminescence

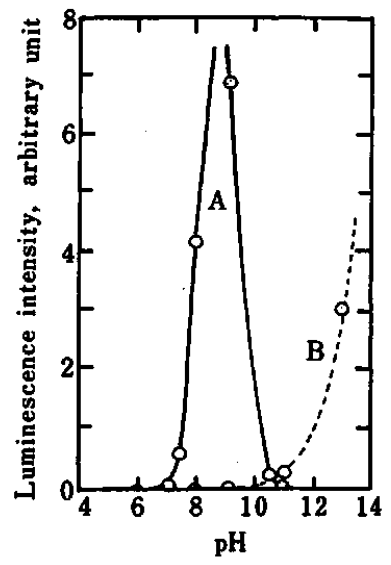

Fig. 4 Effect of $\mathrm{pH}$ on ECL. (A) ECL at appllied potential of $0.7 \mathrm{~V} ; 17 \mu \mathrm{M}$ luminol and 1.32 nmol hydrogen peroxide, (B) background luminescence in the absence of applied potential; $17 \mu \mathrm{M}$ luminol and $1.32 \mu \mathrm{mol}$ hydrogen peroxide.

intensity drastically and even $0.1 \%$ methanol suppressed the light emission by $80 \%$.

A good straight line calibration plot was obtained with the carrier solution (pH 9.2) containing 2\% acetonitrile at the applied potential of $0.7 \mathrm{~V} v$ s. SCE. In this case the detection limit of hydrogen peroxide was as low as $30 \mathrm{pmol}$. When the $\mathrm{pH}$ was 7.4 and the carrier solution did not contain acetonitrile, a straight line calibration plot was obtained with the detection limit of 66 pmol and RSD as low as $1.6 \%$.

It is noteworthy that the half-life of luminescence was very short in the case of luminol. For such a short decay time it is difficult to design an appropriate mixing device for chemiluminescence measurement. The photon counting of luminescence at the electrode surface, however, was especially feasible even for luminescence with very short life-time.

\section{References}

1. C. Blatchford and D. J. Malcome-Lawes, J. Chromatogr., 321, 227 (1985).

2. C. Blatchford, E. Humphreys and D. J. MalcomeLawes, J. Chromatogr., 329, 281 (1985).

3. H. Imai, H. Yoshida, T. Masujima and M. Yanagitani, Bunseki Kagaku, 30, 419 (1981).

4. H. Hwang and P. K. Dasgupta, Anal. Chem., 58, 1521 (1986).

5. T. P. Whitehead, G. H. G. Thorpe, T. J. N. Carter, C. Groucult and L. J. Kricka, Nature [London], 305, 158 (1983).

6. M. Tabata, C. Fukunaga, M. Ohyabu and T. Murachi, J. Appl. Biochem., 6, 251 (1984).

7. M. Maeda and A. Tsuji, Anal. Chim. Acta, 167, 241 (1985).

8. H. Imai, H. Yoshida, T. Masujima and T. Owa, Bunseki Kagaku, 33, 54 (1984).

9. T. Owa, T. Masujima, H. Yoshida and H. Imai, Bunseki Kagaku, 33, 568 (1984). 
10. K. E. Haapakka and J. J. Kankare, Anal. Chim. Acta, 118, 333, (1980).

11. 1. Kamiya, "Chemiluminescence", (Kagakuhakkou, in Japanese) p. 55, Kodansha, Tokyo (1972).

12. P. B. Shevlin and H. A. Newfeld, J. Org. Chem., 35, 2178 (1970).
13. M. M. Rauhut, A. M. Semsel and B. G. Roberts, J. Org. Chem., 31, 2431 (1966).

(Received September 4, 1987)

(Accepted November 5, 1987) 